\title{
Role of Elastin Expression in Thickening the Postpartum Vaginal Wall in Virgin and Postpartum Rat Models
}

\author{
Trisniartami Setyaningrum ${ }^{1,2}$, M. Yulianto Listiawan ${ }^{2}$, Brahmana Askandar Tjokroprawiro ${ }^{3}$, Budi Santoso ${ }^{3}$, Cita \\ Rosita Sigit Prakoeswa ${ }^{2}$, and Widjiati Widjiati ${ }^{* *}$
}

\author{
${ }^{1}$ Post Graduate Doctoral Program, Faculty of Medicine, Universitas Airlangga, Jl. Mayjen Prof. Dr. Moestopo No.47 Surabaya, 60132 Indonesia \\ ${ }^{2}$ Department of Dermatology and Venereology, Faculty of Medicine, Universitas Airlangga, Dr.Soetomo General Hospital Surabaya, Jl. Mayjen Prof. \\ Dr. Moestopo No.47 Surabaya, 60132 Indonesia \\ ${ }^{3}$ Departement of Obstetrics and Gynecology, Faculty of Medicine, Universitas Airlangga, Dr. Soetomo General Academic Hospital, Jl. Mayjen Prof. \\ Dr. Moestopo No.47 Surabaya, 60132 Indonesia \\ ${ }^{4}$ Department of Veterinary Science, Faculty of Veterinary Medicine, Universitas Airlangga, Surabaya, Indonesia \\ * Corresponding author's Email: widjiati@fkh.unair.ac.id; (DORCID: 0000-0002-8376-1176
}

\begin{abstract}
Childbirth induces a number of alterations, including ligament weakening and increased vaginal distensibility. The occurrence of vaginal laxity or distensibility is associated with the vaginal wall and introitus overstretching during vaginal parturition while the pathophysiology is due to increased levator dimension and trauma to the levator ani muscle through avulsion (macrotrauma) or overdistension (microtrauma). Elastin is an extracellular matrix protein that confers elastic properties to organs and tissues, particularly those requiring elasticity. Elastin plays a vital role in the functioning of numerous tissues, such as the lungs, blood vessels, heart valves, ligaments, tendons, and skin. It is also a component of the vaginal mucosa. The aim of the present was to evaluate the role of elastin in the thickening of the postpartum vaginal wall composed of epithelial mucosa, and to understand the mechanism underlying vaginal laxity or distensibility within parous and nulliparous animal models. A total of 32 female white rats (Rattus norvegicus) were used in the present study. They were divided into two groups, each group consisting of 16 rats. The control group ( $\mathrm{C} 0$ ) consisted of virgin nulliparous rats, which were sacrificed on the second day after vaginal parturition. Pregnant rats (group C1) were sacrificed on the second day after vaginal parturition. The median elastin expression in group $\mathrm{C} 1$ was higher $(3 \pm 0.56)$ than group $\mathrm{C} 0(2.85 \pm 0.75)$. The mean thickness of the vaginal mucosal epithelium in group C0 $(56,8931 \mu \mathrm{m})$ was greater than group C1 $(44,98349 \mu \mathrm{m})$. The comparison of vaginal mucosal epithelium thickness between the two groups indicated a significant difference between groups $\mathrm{C} 0$ and $\mathrm{C} 1$. Elastin levels were significantly correlated with epithelial thickness. The expression of elastin significantly affects the vaginal wall thickness, which further affects vaginal laxity or vaginal distensibility.
\end{abstract}

Keywords: Distensibility, Elastin, Vaginal wall, Animals

\section{INTRODUCTION}

Pregnancy causes a number of alterations in the biomechanical behavior of both humans and animals, including ligament weakening and increased vaginal distensibility. The pelvic floor muscles in rats and humans support the protective mechanisms against perineal trauma by increasing stiffness and the extent of sarcomere during parturition. During vaginal delivery, the puborectalis muscle is subjected to several extreme stretching with an estimated stretch ratio of 1.5$3.5 \mathrm{~cm}$ long. The extent to which the muscle elongates varies is between 25\% and 250\% (Qureshi et al., 2018; Gachon et al., 2019).

The commonly associated mechanism with parturition involves overstretching of the vaginal wall and introitus during vaginal delivery, and its pathophysiology is related to increased elevator dimension and trauma to levator ani from avulsion (macrotrauma) and overextension (microtrauma), meaning that vaginal laxity or distensibility is linked to pregnancy and childbirth (Kamisan et al., 2015; Dietz et al., 2016; Abdool et al., 2018).

Shek and Dietz (2009) reported an Ultrasound study that examined the dimensional change of the levator hiatus in postpartum women with and without morphological abnormality, which was then associated with their type of childbirth. Vaginal birth could induce hiatal widening, particularly after an avulsion and even without macroscopic levator trauma, thus potentially enable increasing the hiatal distensibility. Vaginal laxity is the most undesirable symptom, reported by approximately $60.7 \%$ of women. Moreover, levator avulsion occurred in $15 \%$ of women who undergo vaginal delivery. Therefore, It can be inferred that significant changes in the pelvis and distension of the levator hiatus are followed by vaginal delivery (Shek and Dietz, 2009; Abdool et al., 2018).

The pelvic floor muscles play a critical role in female sexual function. A smaller vaginal dimension is linked to sexual dysfunction, particularly dyspareunia. Trauma to the levator ani muscle during childbirth is associated with an increase in vaginal hiatus, which in turn might affect sexual function and vaginal laxity (Roos et al., 2020). 
At the cellular level, vaginal muscles and pelvic supporter are sustained by the integrity of the connective tissue and the attachment between the vagina, sides of the pelvis, and levator ani muscle. The connective tissue as the base of the vagina and its surrounding structures contained collagen, elastin, glycoproteins, hyaluronan, and proteoglycans, which were actively redesigned throughout the woman's life, particularly during hormonal changes (Newman et al., 2018).

Elastin is an extracellular matrix protein that provides elastic properties to organs and tissues, mainly those that require elasticity or are involved in an elongation and shrinkage cycle. Elastinplays a vital role in the functions of numerous tissues, such as the lungs, vessels, heart valves, ligaments, tendons, and skin. Elastin is composed of $90 \%$ elastic fibers and forms an inner core that is surrounded by unbranched microfibrils. Elastin accounts for only two to four percent of the dry skin weight of a human, yet it has an important structural function in providing mechanical support and is involved in various cell signaling pathways. The rate of elastogenesis diminishes with age (Mithieux and Weiss, 2005; Rodríguez-Cabello et al., 2018).

A study by Zong et al. (2010) indicated that comparing elastin metabolism in the female vagina with and without Pelvic Organ Prolapse (POP) found increased levels of tropoelastin, mature elastin, pro Matrix Metalloproteinase (MMP) 9, and active MMP-9 in women with prolapse. The metabolism of elastin was altered in the vagina with prolapse. In addition, the shape of the vaginal tissue rapidly changed in response to mechanical stretching. It was also observed that elastin levels peaked in the absence of hormones. Damage to elastin fibers might be due to increased elastin-degradation enzymes, MMP-2, and MMP-9. Therefore, MMP-2 and MMP-9 levels would decrease along with an increase in the elastin levels in the vagina with POP. The thickening of the elastin fibers in the vaginal wall of patients with anterior POP was due to the remodeling of the extracellular matrix. Moreover, the proximal vagina contained more collagen level in total and less elastin level than its distal counterpart. The vagina is mostly composed of type I collagen, which gives it tensile strength (Zong et al., 2010; Zaki et al., 2016; Rynkevic et al., 2017). Accordingly, to understand the mechanism of elastin in the process of vaginal laxity or distensibility in parous and nulliparous animal models, the role of elastin in postpartum vaginal wall thickening was evaluated in the current study, which is composed of vaginal epithelial mucosa.

\section{MATERIALS AND METHODS}

The present research was an experimental study involving 32 female white rats (Rattus norvegicus). The subjects were allocated into two groups consisting of 16 rats each. Group $1(\mathrm{C} 0)$ or the control group consisted of 16 female rats, nulliparous and virgin, aged 4-5 months with a body weight of 170-200 grams. that were sacrificed on day two, while group 2 (C1) entailed pregnant rats that were sacrificed on the second day following vaginal parturition. Rats were housed in individual rearing cages with dark lighting, monitored air temperature with a flow rate of 5 to $7.5 \mathrm{~km} / \mathrm{hours}$ (gentle breeze), and local humidity with one-atmosphere pressure by inhalation and oxygen demand of 2.68 $\mathrm{ml} /$ gram/hour.

\section{Ethical approval}

Ethics approval of the present research project was obtained from the Ethics Committee of the Health Research Faculty of Veterinary Universitas Airlangga, Surabaya, Indonesia, with the certificate number 2.KE.116.12.2020. All research work was completed in the same institute.

\section{Mating and breeding of female rats}

Previous observations of the estrous cycles were carried out in female ratas using the vaginal swab. Swabs with small cotton swabs moistened with physiological $\mathrm{NaCl}$ were then checked on a glass slide. The cells were then fixed with methanol and stained with $10 \%$ Giemsa solution. Observation of the estrous cycle was carried out under a light microscope with a magnification of $100 \times$.

Female rats were injected with Pregnant Mare Serum Gonadotropin (PMSG) to synchronize the estrous cycle and with human Chorionic Gonadotropin (hCG) to induce superovulation. The 10 IU PMSG was administered intraperitoneally, followed by $10 \mathrm{IU}$ hCG after 48 hours. After the hCG administration, the rats were bred with male rats using a monomating method. Mating was confirmed for the next 17 hours using a vaginal plug. The vaginal plug was composed of coagulated gelatinous secretions that prevented spermatozoa from leaking. Successful copulation was assumed in the presence of a vaginal plug, and it was recorded as day 0 of pregnancy.

\section{Vaginal tissue sampling}

The rats were sacrificed under general anesthesia with ketamine and xylazine. Anesthetic ketamine $\mathrm{n}$ the range of $80-100 \mathrm{mg} / \mathrm{kg}$ mixed with xylazine in the range of $5-10 \mathrm{mg} / \mathrm{kg}$. The intraperitoneal injection dose was $0.2 \mathrm{ml}$ of ketamine-xylazine mixture for each rat. The entire vaginal tissue was swiftly dissected after disinfection with $70 \%$ alcohol. The 
tissues were then split and fixed in $10 \%$ formalin buffer. The collected samples were sent to the pathology laboratory for immunohistochemistry preparation and histopathological examination.

\section{Hematoxylin Eosin staining procedure}

Hematoxylin and eosin stains were used to observe and measure the thickness of the vaginal mucosa. The sliced tissue samples were initially deparaffinized. Then, these tissue slices were fixed in methanol at gradually decreasing concentrations $(100 \%, 90 \%, 80 \%, 70 \%$, and 30\%) then washed in PBS. After immersion in ethanol, tissue slices were placed in hematoxylin for six minutes. After rinsing with water, the slices were consecutively dipped into ammonia and eosin solutions. Sample tissues were then dehydrated and re-fixated in methanol with gradually increasing concentration $(80 \%, 90 \%, 95 \%$, and ethanol absolute), allowed to dry, and thereafter evaluated under a microscope (Cardiff et al, 2014).

\section{Immunohistochemistry evaluation technique}

Immunohistochemical staining was performed to detect elastin expression. The vaginal wall samples were fixed to the object glasses with methanol containing 3\% diluted hydrogen peroxide. Dakocytomation (peroxidase-blocking reagent) was applied to sample parts and then incubated at room temperature with primary antibodies against the monoclonal antibody anti-elastin (monoclonal antibody elastin (BA-4): sc-58756, Santa Cruz Biotechnology, Inc. (1: 300), California, USA). All samples were incubated with biotin-labeled secondary antibodies (Trekkie Universal Link) and incubated overnight with streptavidin-conjugated peroxidase (Trekavidin-HRP Label) and Diaminobenzidine (DAB) as the chromogen. The elastin was counterstained with Mayer's hematoxylin and eosin (Fedchenko and Reifenrath, 2014).

\section{Measurement of vaginal wall thickness and elastin expression}

Vaginal wall thickness was measured using the calibrated Image Raster 3 software. The measurements were performed in 10 microscopy fields at $200 \times$ magnification and counted in 10 different fields. The mean quantitative result $(\mu \mathrm{m})$ of each HE-stained sample was recorded. The evaluation of elastin expression was based on the percentage of the elastin-expressing epithelium of the vaginal mucosa using the Semi-quantitative Immuno_Reactive Score (IRS) method. The mean percentage of the monoclonal antibody-positive vaginal mucosal epithelium was observed under a microscope at 400× magnification in 10 microscopy fields. The Remmele scale index was obtained by multiplying the positive cell percentage score by the color reaction intensity score. A positive cell percentage score was interpreted as score 0 indicating no positive cells, score 1 referring to less than $10 \%$ positive cells, score 2 showing 11-50\% positive cells, Score 3 accounting for $51-80 \%$ positive cells, and Score 4 suggesting more than $80 \%$ positive cells. The color reaction intensity score was interpreted as score 0 meaning no color reaction, score 1 referring to low color intensity, score 2 denoting medium color intensity, and score 3 signifying strong color intensity (Fedchenko and Reifenrath, 2014).

\section{Statistical analysis}

The obtained data were tested for normality using the Kolmogorov-Smirnov test and analyzed using SPSS software (version 24). Furthermore, non-parametric intervariable data were verified using the Mann-Whitney-U Test to determine the differences in parameters between the groups, and statistical significance was set at $\mathrm{p} \leq 0.05$. Parametric data were verified using an independent t-test. The correlation between the two groups was verified using Pearson's correlation test.

\section{RESULTS AND DISCUSSION}

The expression of elastin was monitored using immunohistochemistry and the vaginal wall thickness with hematoxylin and eosin staining. There were differences in elastin expression and vaginal wall thickness between the virgin nulliparous and parous rat groups. The data observed between the treated groups are provided in the following tables and figures.

The results of elastin expression in the vaginal mucosal epithelium are shown in Figure 1. Figure $1 \mathrm{~A}$ represents the elastin expression in vaginal epithelium samples of group $\mathrm{C} 0$, exhibiting a score of 2 with the immunoreactive cells being in the range of 10-50\% in all microscopic fields with a mean expression of $2.85 \pm 0.75$. Figure 1B represents the elastin expression in vaginal epithelial samples from group $\mathrm{C} 1$ with a score of 3 and around 51-80\% immunoreactive cells in all microscopic fields, with a mean expression of $3.0 \pm 0.56$.

Diagram 1 indicates that the median value of elastin expression in group $\mathrm{C} 1$ was higher than that of group $\mathrm{C}$. Differential tests of both groups with the Mann Whitney U-test indicated that the elastin expression in the control group was significantly different from that of the treatment group $\mathrm{C} 1(\mathrm{p}=0.032 ; \alpha<.05$, Table 1$)$. 
Table 1. Mann-Whitney test results of elastin expression in female rats.

\begin{tabular}{|c|c|c|c|c|c|c|}
\hline $\begin{array}{ll}\text { Group } & \text { Elastin Expression } \\
\end{array}$ & $\mathbf{n}$ & Median & $\begin{array}{l}\text { Interquartile } \\
\text { Deviation }\end{array}$ & Minimum & Maximum & P-value \\
\hline Co & 16 & 2.85 & 0.75 & 1.1 & 6.6 & \multirow{2}{*}{$0.032 *$} \\
\hline C1 & 16 & 3.00 & 0.56 & 2.0 & 7.2 & \\
\hline
\end{tabular}

(*) significantat $\mathrm{p}<.05$, group $\mathrm{C} 0$ : Nulliparous female rats, group $\mathrm{C} 1$ : Postpartum female rats.
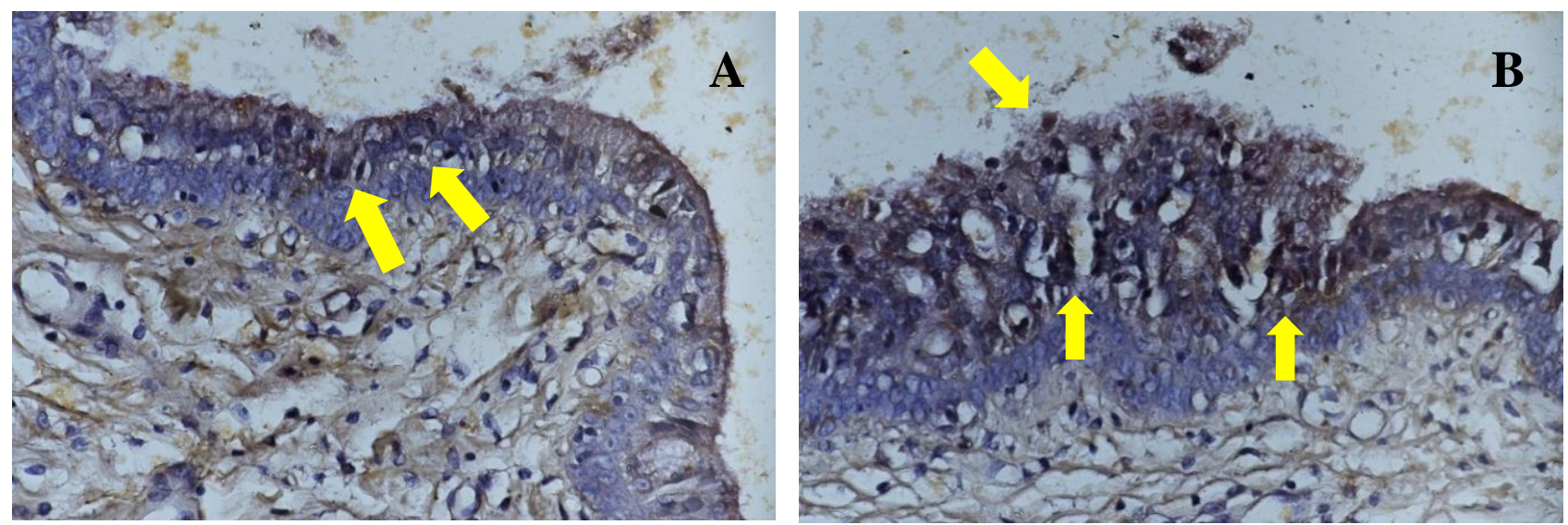

Figure 1. Immunohistochemical results of elastin in female rats. A: Expression of elastin with medium intensity on immunoreactive cells (arrows) in group C0, B: Positive expression with strong intensity is indicated by a brownish dark color on immunoreactive cells (arrows) in group C1, (Immunocytochemistry test; 400× magnification)
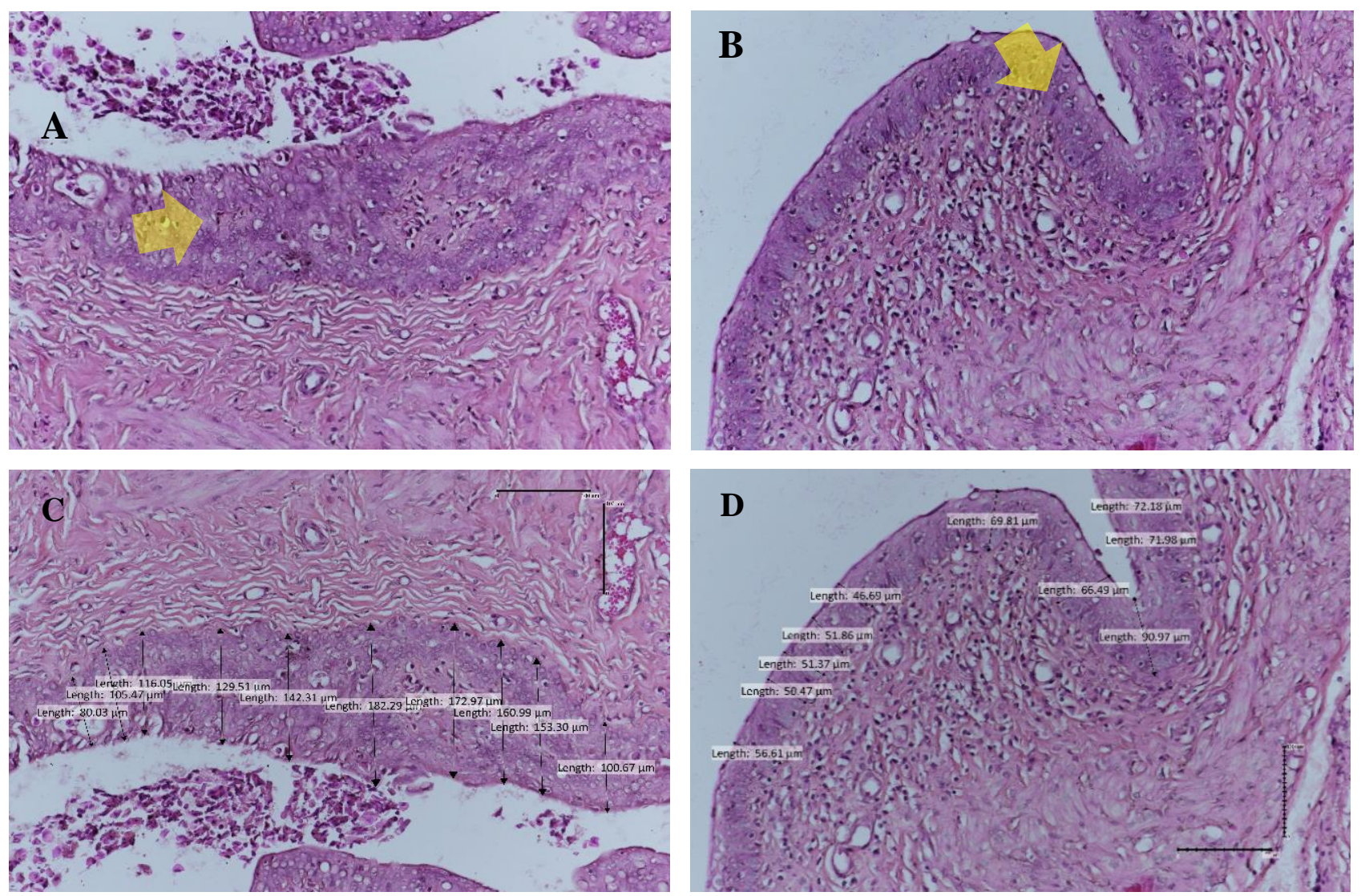

Figure 2. HE-stained samples for vaginal wall/mucosal epithelium thickness measurement. A: Vaginal mucosal epithelium layer (arrow) in group C0, B: Vaginal mucosal epithelium layer (arrow) in group C1, C-D: Measurement of vaginal mucosal epithelium thickness with Image Raster 3 software in groups C0 and C1 (Hematoxylin Eosin; 200x magnification)

\section{Vaginal wall thickness results}

Figure 2 shows a histological representation of vaginal wall thickness, indicated by the vaginal mucosal epithelium thickness. Figure 2A presents the thickness of the mucosal epithelium in group C0 while Figure 2B illustrates the thickness of the mucosal epithelium in group $\mathrm{C}$. Figures $2 \mathrm{C}$ and $2 \mathrm{D}$ show the measurement of the mucosal epithelial thickness of groups $\mathrm{C} 0$ and $\mathrm{C} 1$ with Image Raster 3. Remarkably, the majority of the mucosal epithelial thickness in 
group C0 was greater than that in group C1. Diagram 2 indicates that the mean value of vaginal mucosal epithelial thickness was greater in group C0 $(56,8931 \mu \mathrm{m})$ than in group C1 $(44,98349 \mu \mathrm{m})$. Table 2 shows a comparison of vaginal mucosal epithelium thickness between the groups using an independent t-test. As can be seen, groups $\mathrm{C} 0$ and $\mathrm{C} 1$ exhibited significant differences ( $\mathrm{p}=0.033 ; \alpha<0.05$, Table 2$)$.

Table 2. Differentiation test of vaginal density in female rats.

\begin{tabular}{lcccccc}
\hline \multirow{2}{*}{ Group } & \multicolumn{7}{c}{ Vaginal Density } \\
\cline { 2 - 7 } & $\mathbf{N}$ & Mean & Standard Deviation & Minimum & Maximum & P \\
\hline C0 & 16 & 56.8931 & 16.109954 & 38.205008 & 87.517398 & \multirow{2}{*}{$0.033^{* *}$} \\
\hline C1 & 16 & 44.98349 & 15.116408 & 27.482611 & 77.894783 \\
\hline
\end{tabular}

* Significant at $\mathrm{p}<.05$, group C0: Nulliparous female rats; group C1: Postpartum female rats. N: number of samples. The correlation test between two variables of elastin and epithelial thickness indicated a significant correlation $(\mathrm{p}=0.385 ; \alpha<0.05)$.

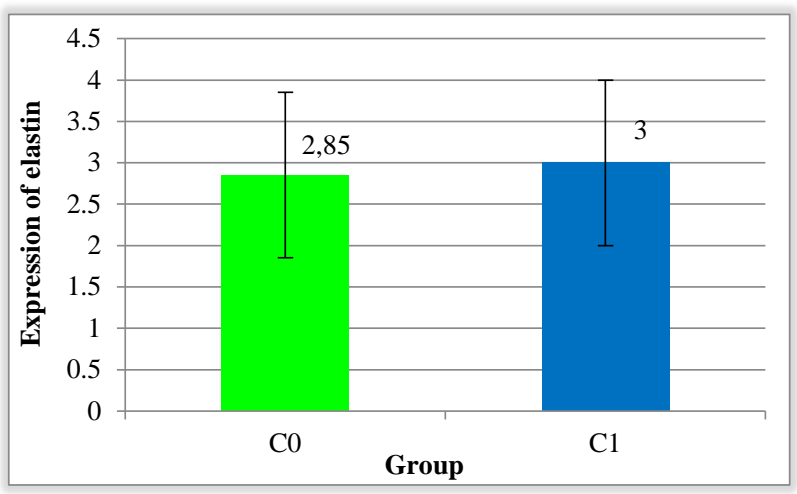

Diagram 1. Median value of expressed of elastin (Group C0: nulliparous female rats; group $\mathrm{C} 1$ : postpartum female rats).

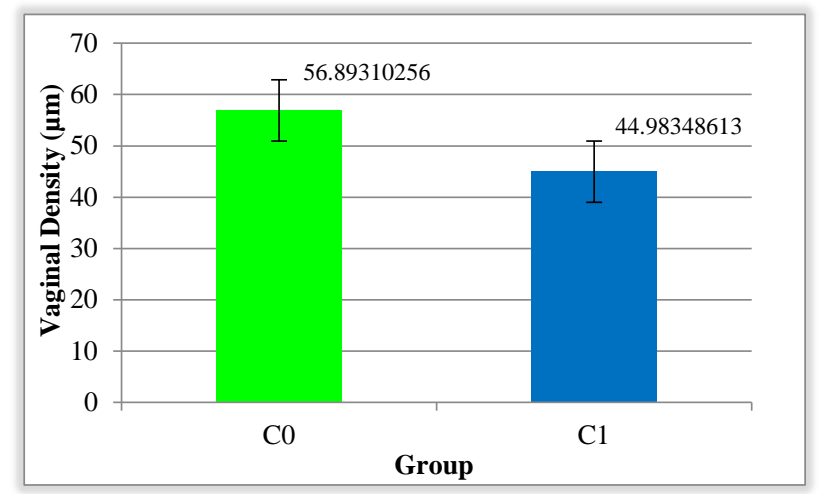

Diagram 2. Mean value of vaginal density (Group C0: nulliparous female rats; group $\mathrm{C} 1$ : postpartum female rats).

The morphology and physiology of the vulva and vagina change with age, especially during puberty (when the menstrual cycle occurs), pregnancy, and menopause. Remodeling of the vaginal wall and pelvic floor connective tissues leads to a rapid increase in the weight of the uterus, as well as the size, due to the deposition of collagen and elastin. The studies in rats with multiple fetuses have shown that the increase in the weight of the uterus is six to eight-fold compared to non-pregnant uteri, while in humans it is 11-fold. It was then shown that collagen content reduced rapidly after parturition. The wet weight has completed $70 \%$ of the involution needed to restore to the baseline value. The collagen removal was $77 \%$ completed and elastin removal was $86 \%$ completed. The vaginal wall consisted of four layers, including stratified, non-keratinized, squamous epithelium, lamina propria, a dense connective tissue layer rich in fibrillar collagen and elastin, filled with fibroblasts, a muscular layer composed of internal circular and external longitudinal smooth muscle fibers, and tunica adventitia, an elastic tissue layer rich in fiber and collagen that supports the vaginal wall. The lamina propria and muscular layer are the two main layers that confer strength to the vaginal wall (De Landsheere et al., 2013; Dhital et al., 2016; Tadir et al., 2017).

In the present study, elastin was expressed more in the postpartum treatment group than in the nulliparous group, with a significant difference. Elastin was modulated by estrogen of the extracellular matrix and fibroblasts, which were responsible for collagen production. The mucosal epithelium functions according to the estrogen level, which naturally reacts to hormonal fluctuations throughout the woman's life, as well as during the menstrual cycle. Postmenopausal women reported having estrogen, whose estradiol levels averaged $14.1 \pm 0.9 \mathrm{pg} / \mathrm{ml}$ and estrone levels averaged $27.5 \pm$ $1.2 \mathrm{pg} / \mathrm{ml}$. Physiological estradiol levels in prepubertal children in the range of approximately $<20 \mathrm{pg} / \mathrm{ml}$, adolescent girls $20-300 \mathrm{pg} / \mathrm{ml}$, adult mestrual women $30-800 \mathrm{pg} / \mathrm{ml}$, and postmenopausal women $<20 \mathrm{pg} / \mathrm{ml}$. During pregnancy, the average levels of estradiol in women were up to $20.000 \mathrm{pg} / \mathrm{ml}$. The ionized epithelium is rich in glycogen fermented by Lactobacilli to decrease vaginal $\mathrm{pH}$ levels. The lamina propria mainly consists of collagen fibers and elastin, and contains dense plexuses of small blood vessels, lymphatic vessels, and nerves. This layer is more populous toward the surface and less populous toward the muscular layer. The lamina propria papillae are scarce on the anterior vaginal wall and grow deeper and stronger toward the posterior wall (Tadir et al., 2017).

In the present study, elastin was more notably expressed in the postpartum treatment group than in the nulliparous group, with a significant difference. This result was in line with a study by Jallah et al. (2014), in which elastin production in nulliparous control animals was higher than in the four and eight weeks post-injury, supported by decreased smooth muscle bundles of the vaginal muscularis. Several other studies supported the fact that postpartum and vaginal wall prolapse samples exhibit diminished amounts of smooth muscle cells and their supporting tissues based on 
immunohistochemical evaluation, both quantitative and qualitative decrease in collagen and elastin (Farouk et al., 2013; Jallah et al., 2014; Kerkhof et al., 2014).

At the cellular level, the MMP-9 expression increased in the postpartum period due to its vital role in regulating type I and III collagen and elastin in vaginal elasticity. An imbalance in the proportion of MMP-9 and type I and III collagen carried the risk of prolapse. Furthermore, fibulin-5 expression played a critical role in elastin synthesis. Fibulin5 was involved in the homeostasis of the extracellular elastin matrix in connective tissues. Moreover, elastin was genetically influenced by the mRNA gene LOX-1. It was also known that elastin synthesis was related to estrogen production. Estrogen participates in modulating the extracellular matrix, smooth muscles, and fibroblasts which are responsible for collagen production. Estrogen production gradually diminishes with age. Estrogen also contributes to childbirth. Elastin production is also vital during parturition to preserve vaginal wall elasticity and maintain structural integrity against the stretching of the vaginal wall. As Word et al. (2009) stated, elastin fibers in humans are synthesized in early life, reach their peak during the third trimester, and gradually decrease by the postnatal period. In a woman's reproductive organs, elastin fiber synthesis is accelerated, particularly during the postpartum period (Word et al., 2009; Downing et al., 2013; Novida, 2013).

In the present study, it has been found that the mean thickness of the vaginal mucosal epithelium was greater in the nulliparous animal model than in the postpartum group. This finding was in accordance with a study conducted by Hamner et al. (2020), who stated that the measured epithelial thickness in the nulliparous group was higher than the postpartum group on the third day. The muscular layer of the vaginal wall was significantly altered during the postpartum period due to uneven thinning of the smooth muscle and smooth muscle bundles. The proliferation of the vaginal mucosal epithelium was hormonally influenced by FBLN5, actionin, and estrogen. Downregulation of ER $\alpha$ correlated with a decreased efficacy of higher doses of estrogen in terms of collagen mRNA, total collagen content, distensibility, and activation of TGF $\beta 1$ gene expression. The estrogen receptor RE- $\beta$ on the stromal and epithelial layers could govern the mitotic activity of cells to differentiate and increase the mucosal epithelial thickness (Montoya et al., 2015; Hamner et al., 2020).

The thinner postpartum vaginal mucosal epithelium might be due to reduced estrogen levels during the postpartum period as well as mechanical factors. During parturition, intra-abdominal pressure increased sharply as part of the fetal expulsion process. These mechanisms have a direct effect on the vaginal wall. This increased mechanical force caused the connective tissue to stretch, which affected the thickness of the vaginal mucosal epithelium, including its extracellular matrix component. According to Young et al. (2017), pregnancy specifically induced the vagina and its supporting connective tissue causing vaginal distensibility. This distensibility reached its maximum point during vaginal childbirth, making the vaginal wall prone to injury, decreased elasticity, and weakness. Other physiological factors that affect the dilation of the vaginal wall and uterus include fetal size, mechanical contraction, and distension of uteri (Zaki et al., 2016; Young et al., 2017).

\section{CONCLUSION}

The tissues of the female reproductive tract are significantly remodeled and altered to allow the fetus to grow and give birth. Elastin production is a vital part of the extracellular matrix in the uterus and vaginal wall, which is remodeled during parturition and at various stages of pregnancy. This study highlights that the expression of elastin significantly influences the vaginal wall thickness, leading to vaginal distensibility that affects collagen structure in pregnancy and parity.

\section{DECLARATIONS}

\section{Authors' contribution}

Trisniartami Setyaningrum performed research concept and design, wrote the article, and approved the article. M. Yulianto Listiawan performed the collection and/or assembly of data. Brahmana Askandar Tjokroprawiro performed measurements and analyzes experimental data. Widjiati wrote the article and final approval of the article. Budi Santoso performed a critical revision of the article. Cita Rosita Sigit Prakoeswa performed a critical revision of the article. All authors approved the final draft of the manuscript for submission to this journal. Ethical issues (including plagiarism, consent to publish, misconduct, data fabrication and/or falsification, double publication and/or submission, and redundancy) have been checked by the authors.

\section{Competing interests}

The authors have not declared any conflict of interest.

\section{Acknowledgments}

We would like to express our deep gratitude to all staff of the animal laboratory who support this research project. The authors also acknowledge the research facilities provided by Animal Laboratory in Faculty of Veterinary Medicine Universitas Airlangga Surabaya, Indonesia. 


\section{Ethical considerations}

All authors should not submit manuscripts that are concurrently under consideration for publication in another journal or have already been published as a peer-reviewed publication. Duplicate submission and concurrent publication are highly unethical publishing behavior.

\section{REFERENCES}

Abdool Z, Lindeque BG, and Dietz HP (2018). The impact of childbirth on pelvic floor morphology in primiparous Black South African women: A prospective longitudinal observational study. International Urogynecology Journal, 29(3): 369-375. DOI: https://www.doi.org/10.1007/s00192-017-3530-1

Cardiff RD, Miller CH, and Munn RJ (2014). Manual hematoxylin and eosin staining of mouse tissue sections. Cold Spring Harbor Protocols, 6: 655-658. DOI: https://www.doi.org/10.1101/pdb.prot073411.

De Landsheere L, Munaut C, Nusgens B, Maillard C, Rubod C, Nisolle M, Cosson M, and Foidart JM (2013). Histology of the vaginal wall in women with pelvic organ prolapse: A literature review. International Urogynecology Journal, 24(12): 2011-2020. DOI: https://www.doi.org/10.1007/s00192-013-2111-1

Dhital B, Gul-E-Noor F, Downing KT, Hirsch S, and Boutis GS (2016). Pregnancy-induced dynamical and structural changes of reproductive tract collagen. Biophysical Journal, 111(1): 57-68. DOI: https://www.doi.org/10.1016/j.bpj.2016.05.049

Dietz HP, Wilson PD, and Milsom I (2016). Maternal birth trauma: Why should it matter to urogynaecologists? Current Opinion in Obstetrics and Gynecology, 28(5): 441-448. DOI: https://www.doi.org/10.1097/GCO.0000000000000304

Downing KT, Strobe FA, Mikhail MS, and Disanto ME (2013). Pregnancy with and without birth trauma modulates the gene expression of proteins involved in elastic fiber homeostasis in the rat vagina. Open Journal of Obstetrics and Gynecology, 3(08): 603-608. DOI: https://www.doi.org/10.4236/ojog.2013.38108

Farouk H, Fatah AA, Ibrahim K, and Helmy W (2013). Vaginal wall changes in muscles and connective tissues after vaginal birth. Life Science Journal, 10: 2816-2823. DOI: https://www.doi.org/10.7537/marslsj100113.339.

Fedchenko N, and Reifenrath J (2014). Different approaches for interpretation and reporting of immunohistochemistry analysis results in the bone tissue - a review. Diagnostic pathology, 9: Article number 221. DOI: https://www.doi.org/10.1186/s13000-014-02219.

Gachon B, Nordez A, Pierre F, and Fritel X (2019). Tissue biomechanical behavior should be considered in the risk assessment of perineal trauma at child birth. Archives of Gynecology and Obstetrics, 300: 1821-1826. DOI: https://www.doi.org/10.1007/s00404-019-05369-5

Gunja-Smith Z, Lin J, and Woessner JF (1989). Changes in desmosine and pyridinoline crosslinks during rapid synthesis and degradation of elastin and collagen in the rat uterus. Matrix, 9: 21-27. DOI: https://www.doi.org/10.1016/s0934-8832(89)800149.

Hamner J, Florian-Rodriguez M, Acevedo J, Shi H, and Word RA (2020). Protease inhibition improves healing of the vaginal wall after obstetrical injury: Results from a preclinical animal model. Scientific Reports, 10(6358): 1-11. DOI: https://www.doi.org/10.1038/s41598-020-63031-6

Jallah ZC (2014). The role of vaginal smooth muscle in the pathogenesis of pelvic organ prolapsed. Thesis, Swanson School of Engineering, University of Pittsburgh, United States. p. 181. Available at: https://core.ac.uk/download/pdf/33561719.pdf

Kamisan AI, Gerges B, Shek KL, and Dietz HP (2015). The association between vaginal parity and hiatal dimensions: A retrospective observational study in a tertiary urogynaecological centre. International Journal of Obstetrics and Gynaecology, 122(6): 867872. DOI: https://www.doi.org/10.1111/1471-0528.12920

Kerkhof MH, Ruiz-Zapata AM, Bril H, Bleeker MC, Belien JA, Stoop R, and Helder MN (2014). Changes in tissue composition of the vaginal wall of premenopausal women with prolapse. American Journal of Obstetrics and Gynecology, 210(2): 168.e1168.e9. DOI: https://www.doi.org/10.1016/j.ajog.2013.10.881

Mithieux SM, and Weiss AS (2005). Elastin. Advances in Protein Chemistry, 70: 437-461. DOI: https://www.doi.org/10.1016/S00653233(05)70013-9

Montoya TI, Maldonado PA, Acevedo JF, and Word RA (2015). Effect of vaginal or systemic estrogen on dynamics of collagen assembly in the rat vaginal wall. Biology of Reproduction, 92(2): 1-9. DOI: https://www.doi.org/10.1095/biolreprod.114.118638

Newman R, Campbell P, Gooneratne M, Lowenstein L, Mu G, Qureshi A, and Krychman M (2018). Genito pelvic vaginal laxity: Classification, etiology, symptomatology, and treatment considerations. Current Sexual Health Reports, 10: 222-236. DOI: https://www.doi.org/10.1007/s11930-018-0168-z

Novida A (2013). Differences in expression of mmp-9 and timp-1 in nullipara and postpartum studies on the anal levator muscle, vaginal wall and sacrouterine ligament of rat rattus norvegicus. Magister thesis, Universitas Brawijaya, Indonesia. Available at: http://repository.ub.ac.id/158562/

Qureshi AA, Sharma K, Thornton M, Myckatyn TM, and Tenenbaum MM (2018). Vaginal laxity, sexual distress, and sexual dysfunction: A cross-sectional study in a plastic surgery practice. Aesthetic Surgery Journal, 38(8): 873-880. DOI: https://www.doi.org/10.1093/asj/sjx255

Rodríguez-Cabello JC, González de Torre I, Ibañez-Fonseca A, and Alonso M (2018). Bioactivescaff olds based on elastin-like materials for wound healing. Advanced Drug Delivery Reviews, 129: 118-133. DOI: https://www.doi.org/10.1016/j.addr.2018.03.003

Roos AM, Speksnijder L, and Steensma AB (2020). Postpartum sexual function; the importance of the levatorani muscle. International Urogynecology Journal, 31(11): 2261-2267. DOI: https://www.doi.org/10.1007/s00192-020-04250-3

Rynkevic R, Martins P, Hympanova L, Almeida H, Fernandes AA, and Deprest J (2017). Biomechanical and morphological 
properties of the multiparous ovine vagina and effect of subsequent pregnancy. Journal of Biomechanics, 57: 94-102. DOI: https://www.doi.org/110.1016/j.jbiomech.2017.03.023

Shek KL, and Dietz HP (2009). The effect of child birth on hiatal dimensions. Obstetrics and Gynecology, 113(6): 1272-1278. DOI: https://www.doi.org/110.1097/AOG.0b013e3181a5ef23

Tadir Y, Gaspar A, Lev-Sagie A, Alexiades M, Alinsod R, Bader A,Calligaro A, Elias JA, Gambaciani M, Gaviria JE et al. (2017). Light and energy based therapeuticsfor genitourinary syndrome of menopause: Consensus and controversies. Lasers in Surgery and Medicine, 49: 137-159. DOI: https://www.doi.org/110.1002/lsm.22637

Word RA, Pathi S, and Schaffer JI (2009). Pathophysiology of pelvic organ prolapse. Obstetrics and Gynecology Clinics of North America, 36(3): 521-539. DOI: https://www.doi.org/110.1016/j.ogc.2009.09.001

Young N, Rosamilia A, Arkwright J, Lee J, Davies-Tuck M, Melendez J, Werkmeister J, and Gargett C (2017). Vaginal wall weakness in parous ewes: A potential preclinical model of pelvic organ prolapses. International Urogynecology Journal, 28(7): 999-1004. DOI: https://www.doi.org/110.1007/s00192-016-3206-2

Zaki A, Mardian K, and Mustokoweni S (2016). Increased thickness of elastin fibre on vaginal wall of aiunterior pelvic organ prolapse. Majalah Obstetri and Ginekologi, 24: 31-36. DOI: https://www.doi.org/10.20473/mog.V24I12016.31-36

Zong W, Stein SE, Starcher B, Meyn LA, and Moalli PA (2010). Alterationof vaginal elastin metabolism in women with pelvic organ prolapse. Obstetrics and Gynecology, 115: 953-961. DOI: https://www.doi.org/110.1097/AOG.0b013e3181da7946 